\title{
NEWS FROM THE URBAN FRONT: ADRESSING SOCIAL INNOVATION IN URBAN AND REGIONAL MANEGMENT
}

\author{
Gerhard Braun, James Scott \\ Deptartment of Geography, Freie Universität Berlin, Maleserstr. \\ 74-100, Berlin, Germany \\ e-mail: gbraun@geog.fu-berlin.de
}

\begin{abstract}
Despite the multifarious nature of urban change, and of the scientific perspectives available for the comprehension of that change, urban management is an issue that crosses cultural divides and affects all aspects of urban development. What is required is social innovation in Urban Management in order to create feasible opportunity structures for sustainable and equitable development. However, how can this be done? Social innovation - and a transformation of social institutions - is needed in order to comprehend and address the complexity of metropolitan development processes. New forms of metropolitan governance based on multiactor partnerships, collaborative policy fora and (importantly) a new urban spatial imagery, address the failure of traditional institutions to address growth/shrinkage, planning and social equity issues. Formal planning paradigms upon which urban planning has relied for decades have often been compartmentalised and inherently limited in scope. Based on a discussion with US-American experiences with the notion of "Smart Growth", we will examine some of the lessons that have been learned and discuss their applicability to other urban contexts.
\end{abstract}

Key words: Fragmentation, governance, network interaction, new regionalism, polarisation, smart growth 